Article

\title{
Proposal Design of a Hybrid Solar PV-Wind-Battery Energy Storage for Standalone DC Microgrid Application
}

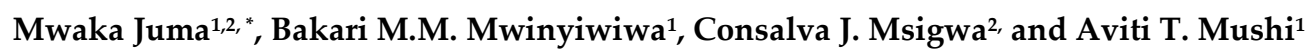 \\ 1 Electrical Engineering Department, University of Dar es Salaam, Dar es Salaam, \\ Tanzania; bakari1mwinyiwiwa@gmail.com, https://orcid.org/0000-0001-7377-665X \\ (B.M.); aviti.thadei@udsm.ac.tz, https://orcid.org/0000-0002-2958-2919 (A.M.) \\ 2 Electrical Department, Dar es Salaam Insititute of Technology, Dar es Salaam, \\ Tanzania, msigwaj34@gmail.com (C.M.) \\ * Correspondence: jumamwaka@gmail.com
}

Abstract: This paper presents a microgrid distributed energy resources (DERs) for a rural standalone system. It is made up of solar photovoltaic (solar PV) system, battery energy storage system (BESS), and wind turbine coupled to permanent magnet synchronous generator (WT-PMSG). The DERs are controlled by maximum power point tracking (MPPT) based proportional intergral (PI) controllers for both maximum power tracking and error feedback compensation. The MPPT uses the perturb and observe (P\&O) algorithm for tracking the maximum power point of the DERs. The PI gains are tuned using the Ziegler-Nichol's method. The developed system was built and simulated in MATLAB/Simulink under two conditions - constant load, and step load changes. The controllers enabled the BESS to charge even during conditions of varying load and other environmental factors such as change of irradiance and wind speed. The reference was tracked very well by the output voltage of the DC grid. This is a useful research for electrifying the rural islanded areas, too far from the grid.

Keywords: Solar Photovoltaic (PV), Wind turbine coupled to permanent magnet synchronous generator (WT-PMSG), Battery energy storage system (BESS), Maximum Power Point Tracking (MPPT), and DC/DC converters

\section{Introduction}

Recent research has shown that in Tanzania, the access to electricity is limited to $35.6 \%$ of the total 56.32 million population as of year 2018 [1]. This problem of limited access to electricity can be reduced not only by grid expansions, rather, by utilizing distributed renewable energy sources (RES). These systems such as solar home systems (SHS), micro- and mini-solar plants are increasingly being used as sources of electric energy in rural areas worldwide. They are designed for use at small household demand usually in power ranging in few kilowatts. Thereby causing limitations for enterprise and other potentially larger users of electricity within rural areas. 
Solar photovoltaic (PV) plants need big power storage (such as batteries) to provide voltage regulation, and reduce the effects of the energy source intermittency, which adds to the cost of the installation. To reduce the cost of battery, it has been proposed to integrate several RES to form a hybrid power system [2]. Therefore, there exists a need to manage the flow of energy on these hybrid RES to ensure the reliability and availability of power supply to meet load demand. However, control of these hybrid RES systems is usually a difficult task [3]. One very complex task is to control these hybrid RES distributed energy sources (DERs) in a micro grid to maintain voltage of the micro grid within an acceptable range of $\pm 5 \%$ of the DC bus voltage [4]. This paper will review briefly previous proposed control architectures and point out their limitations.

The traditionally employed active-reactive (PQ) droop control has been applied in power control of a microgrid, which has success in grid-connected mode. However, the PQ droop control fails miserably when the microgrid goes into islanded mode due to poor reactive and resistive $(X / R)$ ratio [5, 6]. Another researcher [7] proposed to limit the stochastically varying DERs output by interfacing them to the DC grid using a SEPIC converter. The method works well to eliminate the effects of SEPIC voltage input (from the DERs) variation and step load changes. Further, artificial neural network (ANN) and fuzzy logic controllers (they can be summed up as artificial intelligence - AI) have been employed to satisfy load requirements from a microgrid [8]. However, the large number of connected DERs, which sometimes impose those AI controllers to fulfil conflicting requirements is fraught with limited communication. Microgrid central controller (MGCC) has been installed either on low voltage side or low voltage substation [9]. This architecture is complex, expensive, and is not feasible for implementation in DERs located in rural areas of many developing nations.

Voltage regulation on the DC bus of a microgrid has been accomplished extensively in the surveyed literature [5, 10-14], however, still there occurs voltage dip and swell whenever the inputs, control, and outputs (loads connected to the DC bus) change abruptly. Therefore, this paper proposes a control system for the RES to maintain the DC bus voltage at $750 \mathrm{~V}$ irrespective of the varying solar irradiance, DC grid load step change, and wind speed changes.

\section{Materials and Methods}

This paper considers the following energy resources constituting the microgrid DERs for a rural standalone system - solar PV plant rated $31.5 \mathrm{~kW}$; wind turbine equipped with permanent synchronous generator (WT-PMSG) rated $6 \mathrm{~kW}$; and battery storage rated $248 \mathrm{Ah}(6.4 \mathrm{~kW})$ respectively as shown in Figure 1. The solar PV plant gives out intermittent power from the solar irradiation at a DC voltage of about $547 \mathrm{~V}$, thus the DC/DC boost converter steps up this voltage to a steady output of $750 \mathrm{~V}$ and feeds it to the DC bus. The WT-PMSG gives intermittent output AC voltage of $500 \mathrm{~V}$, which is rectified by the AC/DC rectifier to DC voltage of $477 \mathrm{~V}$, and then this voltage is stepped up to $750 \mathrm{~V}$ through the boost DC/DC converter. Lastly, but not the least is the battery energy storage system (BESS) at $240 \mathrm{~V}$ DC. The battery gets charged through the bidirectional DC/DC converter (BDC) and discharges through the same. 


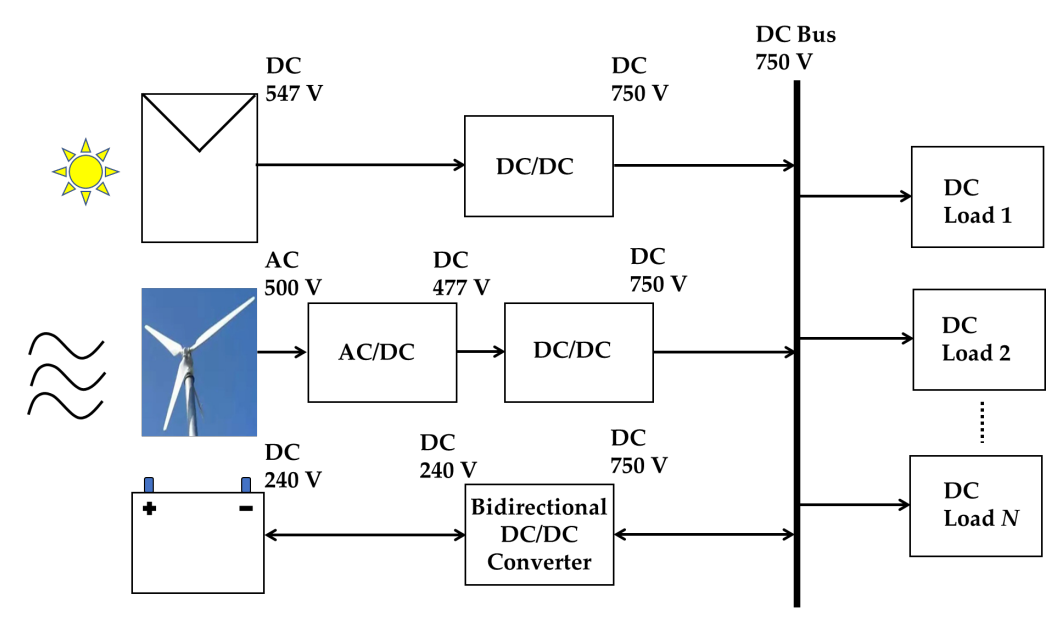

Figure 1. Microgrid DERs for a rural standalone system

\subsection{Solar PV array modelling}

Solar PV array is made up of series ( $\left.N_{S S}\right)$ connected modules, and a string of these modules are together strung in a parallel $\left(N_{P P}\right.$ ) connection. Therefore, using the diode model of a solar cell [15], the total current $I_{P V, T o t}$ that comes out of the solar PV array is presented by [16] in (1) - (4). The solar module current is $I_{P V}, R_{S}$ and $R_{P}$ are solar cell series and shunt resistances respectively. The adopted diode model of a solar cell has dark saturation current $I_{0}$, harvested solar cell current $I_{P V}$, diode ideality factor $a$, diode thermal voltage $V_{T}$. The Boltzmann constant is $k=1.380 \times 10^{-23} \mathrm{~J} / \mathrm{K}, T$ is the temperature of the cell, and $q=1.6022 \times 10^{-19} \mathrm{C}$ is the elementary charge. The voltage ratio $\kappa$ and current ratio $\chi_{I}$ are used to simplify the equations (1) through (4).

$$
\begin{aligned}
I_{P V, T o t} & =N_{P P}\left(I_{P V}-I_{0}\left(\mathrm{e}^{\kappa}-1\right)\right)-\chi_{I} \\
\kappa & =\frac{N_{P P} V_{P V, T o t}+N_{S S} R_{S} I_{P V, T o t}}{a N_{S S} N_{P P} V_{T}} \\
\chi_{I} & =\frac{N_{P P} V_{P V, T o t}+N_{S S} R_{S} I_{P V, T o t}}{N_{S S} R_{P}} \\
V_{T} & =\frac{k T}{q}
\end{aligned}
$$

The $I_{0}$ is a function of the bandgap energy $E_{g}=1.12 \mathrm{eV}$ at nominal temperature $T_{n}=25{ }^{\circ} \mathrm{C}$, with a nominal saturation current $I_{0, n}$ as captured by (5) - (8). Solar cell nominal short circuit current is represented by $I_{s c, n}$, with nominal open circuit voltage represented by $V_{o c, n}$. For series $N_{S S}$ connected solar modules, the thermal voltage is $V_{T, n}$. Other placeholder variables defined by $\varpi$, and $v$ are used for convenience.

$$
\begin{aligned}
& I_{0}=I_{0, n}\left(\frac{T_{n}}{T}\right)^{3} e^{\varpi} \\
& \varpi=\frac{9 E_{g}}{a k}\left(\frac{1}{T_{n}}-\frac{1}{T}\right) \\
& I_{0, n}=\frac{I_{s c, n}}{e^{v}-1}
\end{aligned}
$$




$$
v=\frac{V_{o c, n}}{a V_{T, n}}
$$

The $I_{P V}$ dependence on the solar irradiance $G$ is presented by (9), where nominal irradiance is $G_{n}=1000 \mathrm{~W} / \mathrm{m}^{2}, K_{i}$ is the short circuit current/temperature coefficient, and $I_{P V, n}$ is the nominal current at nominal conditions.

$$
I_{P V}=\left(I_{P V, n}+K_{i}\left(T-T_{n}\right)\right) \frac{G}{G_{n}}
$$

\subsection{Wind turbine modeling}

The wind power $P_{w}$ extracted from the variable wind speed $V_{w}$, with turbine blades cutting an area $A$ is (10) as presented by Haque et al. [17]. The Betz limit $C_{p}$ (11) is a function of blade pitch angle $\beta$, and tip speed ratio $\lambda$ (12). Radius of the shaft that is coupled to the rotor of the generator is $R$, rotating at an angular speed $w$. Betz limit has a maximum value equal to 0.593 [18].

$$
\begin{aligned}
& P_{w}=0.5 \rho A V_{w}^{3} C_{p}(\beta, \lambda) \\
& C_{p}=0.5\left(\lambda-0.022 \beta^{2}-5.6\right) e^{-0.17 \lambda} \\
& \lambda=\frac{w R}{V_{w}}
\end{aligned}
$$

Smaller wind turbines have fixed $\beta$, therefore for this case $C_{p}$ is a function of $\lambda$ alone. For every $V_{w}$, there is a different optimal $\lambda$. Thus, coupling a generator with variable speeds enables maximum power extraction at different $V_{w}$.

\subsubsection{Modelling of permanent magnet synchronous generator}

The permanent magnet synchronous generator (PMSG) that is coupled to the wind turbine is modeled in direct-quadrature (d-q) synchronous frame [18], by the following expressions.

$$
\begin{aligned}
& v_{d}=-R_{s} i_{d}-L_{d} \frac{d i_{d}}{d t}+L_{q} i_{q} w \\
& v_{q}=-R_{s} i_{q}-L_{q} \frac{d i_{q}}{d t}+L_{d} i_{d} w+\phi_{m} w
\end{aligned}
$$

Direct and quadrature axes' voltages and currents are: $v_{d}, v_{q}, i_{d}$, and $i_{q}$ respectively. Respective inductances are $L_{d}$ and $L_{q}$. The stator resistance is denoted by $R_{s}$, while $w$ is the electrical angular speed. The PMSG establishes a magnetic flux linkage $\phi_{m}$, thus the electromagnetic torque $T_{e}$ is computed by (15), where $p$ is the number of pole pairs of the PMSG. Since the PMSG has a cylindrical rotor, the $L_{d}=L_{q}$, then (15) simplifies to (16).

$$
\begin{aligned}
& T_{e}=1.5 p\left(\left(L_{d}-L_{q}\right) i_{d} i_{q}+\phi_{m} i_{q}\right) \\
& T_{e}=1.5 p \phi_{m} i_{q}
\end{aligned}
$$

\subsection{DC/DC boost converter}

The unregulated DC voltage output from the solar PV array or the rectifier of the PMSG needs to be regulated to a higher DC voltage of the DC bus as shown in Figure 1. 
This is accomplished by the DC/DC boost converter, whose steady state continuous current conduction mode operation is represented by (17) - (18) as found in [19-21]. The steady state duty cycle is denoted by $D \in(0,1)$. Denote the unregulated input voltage/current to the boost converter by $V_{i n} / I_{\text {in }}$ and the regulated output voltage/current by $V_{D C} / I_{D C}$. Therefore, the boost converter's inductance $L$ and capacitance $C$ are computed in (19) - (20) respectively, following the work of [22]. The DC load is modeled by resistor $R$, and the boost converter is switching at a frequency of $f_{s}=20 \mathrm{kHz}$, with an allowed voltage ripple $\Delta V_{D C}$.

$$
\begin{aligned}
& V_{D C}=\frac{V_{\text {in }}}{1-D} \\
& I_{D C}=I_{\text {in }}(1-D) \\
& L \geq \frac{D(1-D)^{2} R}{2 f_{s}} \\
& C \geq \frac{D}{\Delta V_{D C} f_{s} R}
\end{aligned}
$$

\section{Maximum Power Point Tracking based Proportional and Integral Controller}

This section discusses the maximum power point tracking (MPPT) control method that is used with the proportional integral (PI) controller to undertake the DC bus voltage regulation. Consider the DC/DC boost converter with a source (e.g., solar PV array), and the MPPT based PI controller shown by Figure 2. With the solar panel as shown in Table 2, there is the input voltage $V_{P V}$ smoothing capacitor $C_{P V}$, and inductor $L_{P V}$ through which the input current $I_{P V}$ flows. The converter's switch $Q_{P V}$ is turning ON and OFF at the switching frequency, $f_{s}$ so that the diode delivers charging current to the output capacitor $C_{d c}$. At steady state, the boost converter delivers output current $I_{d c}$ and voltage $V_{d c}$ to the DC grid.

The MPPT based PI controller processes the measurements of $V_{P V}, I_{P V}$ and $V_{d c}$ to produce the switching duty cycle $D[k] \in(0,1)$, where $k$ is the discrete time instant. Each controller will be explained separately in the following subsections.

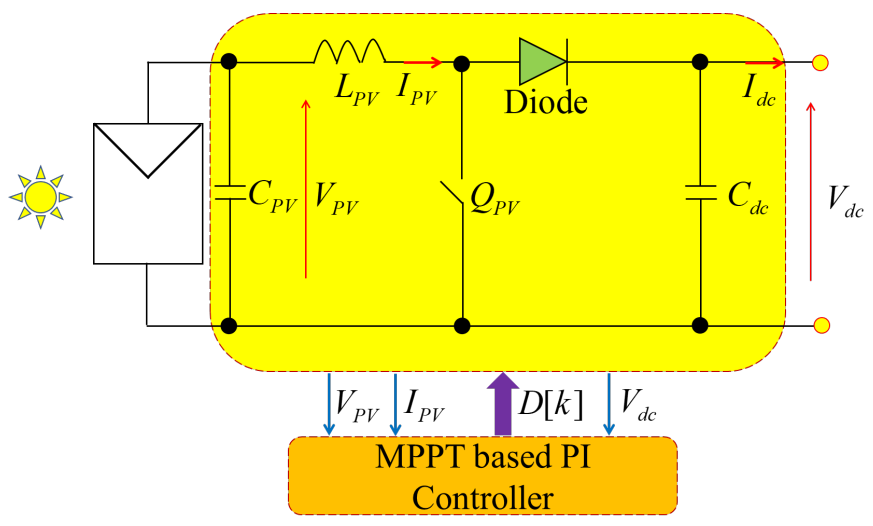

Figure 2. Equivalent circuit of boost DC/DC converter with MPPT based PI control 


\subsection{Maximum power point tracking controller}

Researchers [10, 23], have presented an MPPT technique using the Perturb and Observe $(\mathrm{P} \& \mathrm{O})$ algorithm, which this paper adopts because of its simplicity to apply. In discrete time $k$ domain, the $\mathrm{P} \& \mathrm{O}$ algorithm tracks the maximum power by using the measurements of the input voltage $V[k]$ and current $I[k]$ of the source . Then, determining the power $P[k]$, which is used in adjusting the $D[k]$ accordingly to always harvest maximum power. This duty cycle $D[k]$ is computed from (21) by updating the previous sampling instant $k-1$ duty cycle $D[k-1]$ in (21) accordingly as Figure 3 shows.

$$
D[k]=D[k-1] \pm d D[k]
$$

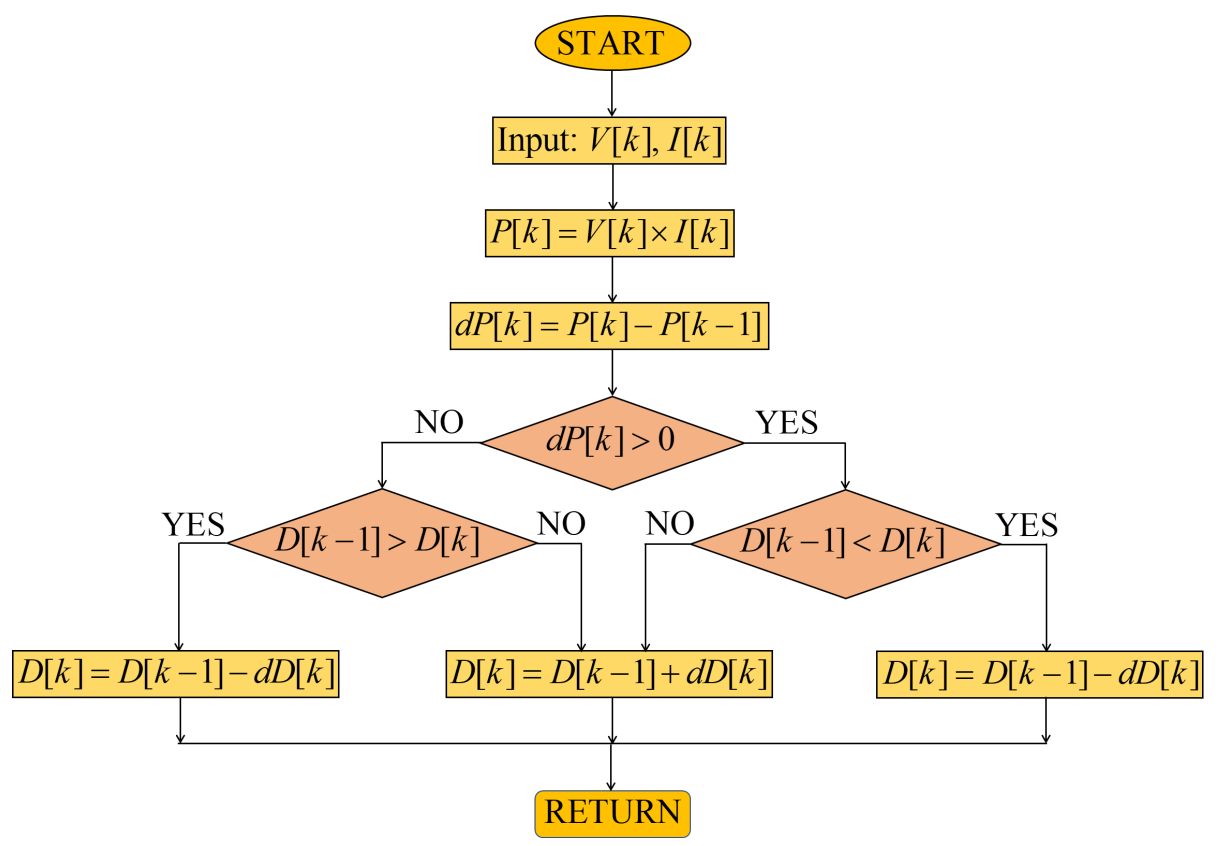

Figure 3. Flow chart of MPPT using P\&O algorithm

\subsection{Proportional integral controller}

The PI controller is used as a feedback compensation control algorithm in several industrial applications worldwide. For example, a PI controller was implemented to provide compensation for DC/DC boost converter [24] and a microgrid [25]. Given a system reference signal $r[k]$, output signal $y[k]$, where the output deviation from reference is $e[k]=r[k]-y[k]$, then it follows that the PI will provide control compensation $u[k]$ presented in (22) that is fed to the system to eliminate the deviation. The PI gains $k_{P}$ and $k_{I}$ are tuned using Ziegler-Nichol's method shown in Table 1.

$$
u[k]=u[k-1]+k_{P}(e[k]-e[k-1])+k_{I} e[k]
$$

\begin{tabular}{lc}
\hline \multicolumn{2}{c}{ Table 1: Tuning the PI gains } \\
\hline Gain & Values
\end{tabular}




\begin{tabular}{ll}
$k_{p 1}$ & 0.5 \\
$k_{i 1}$ & 0.6 \\
$k_{p 2}$ & 0.5 \\
$k_{i 2}$ & 0.001 \\
\hline
\end{tabular}

\subsection{DC bus voltage regulation design for solar $P V$}

The DC-DC Boost Converter regulates the DC bus voltage through MPPT control and PI control algorithms, discussed in the previous subsections. The MPPT control output is shown by (21), while the one from the PI is shown by (22). One should note that the reference $r[k]$ of (22) is replaced by $V_{d c, \text { ref }}[k]$ and the measured output $y[k]$ is replaced by measured DC bus voltage $V_{d c}[k]$. Therefore, any discrepancy on the input or output is corrected by the MPPT and the PI controller in tandem. Thereafter, this paper proposes a second PI which now performs additional corrective measures on the error generated from interaction between MPPT and the PI. To validate this new (proposed) control algorithm, the DC/DC boost converter with parameters found in Appendix Table $2[11,26]$ is simulated using MATLAB/Simulink. The PI gains are tuned to those shown by Table 1 .

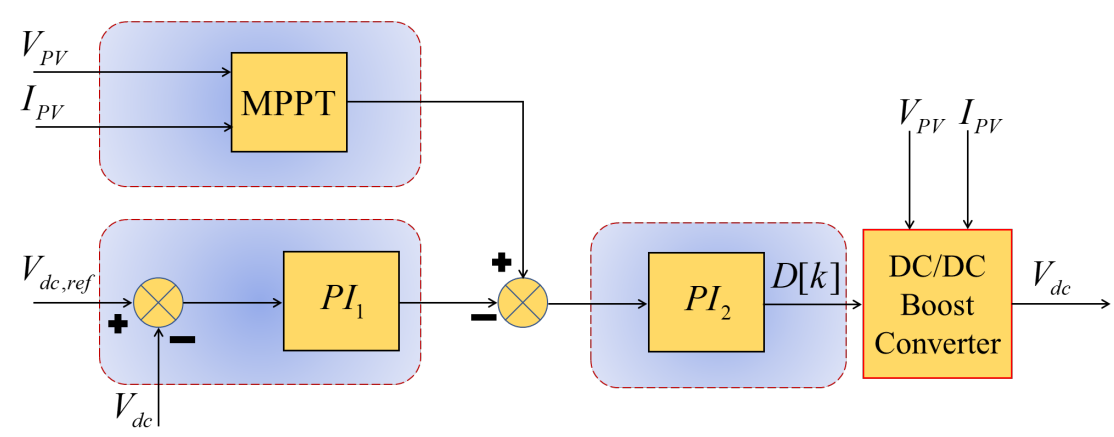

Figure 4. DC bus voltage regulation by MPPT based PI control

\subsection{Solar PV with battery energy storage system}

Rajasekaran and Usha Rani [27] proposed a bidirectional DC/DC (BDC) converter to interface the battery to the DC microgrid. The interface is undertaken on the DC link with the boost DC/DC converter of the solar PV as shown in Figure 5. This converter is required to protect the battery from over and under charge through suitable control algorithm. Furthermore, it has to have a wide current capacity to be capable of handling high current during low voltage operations. Similarly, this paper proposes to employ the $\mathrm{BDC}$, shown by Figure 5 to maintain the DC grid voltage at $750 \mathrm{~V}$. The battery voltage level is represented by $V_{b}$. The BDC inductor is $L_{b}$ which can pass the charge/discharge current $I_{b}$. The BDC switch is $Q_{b-b}$ operates at frequency of $f_{s}$ or any other depending on the design is the one responsible for the boost mode. The switch that is responsible for the buck mode is $Q_{c-d}$ operating at $f_{s}$. The battery charges in the buck mode, and discharges in the boost mode. Another research group [28] presented this converter as capable of adaptive power management and control, therefore it is suitable for this application. 


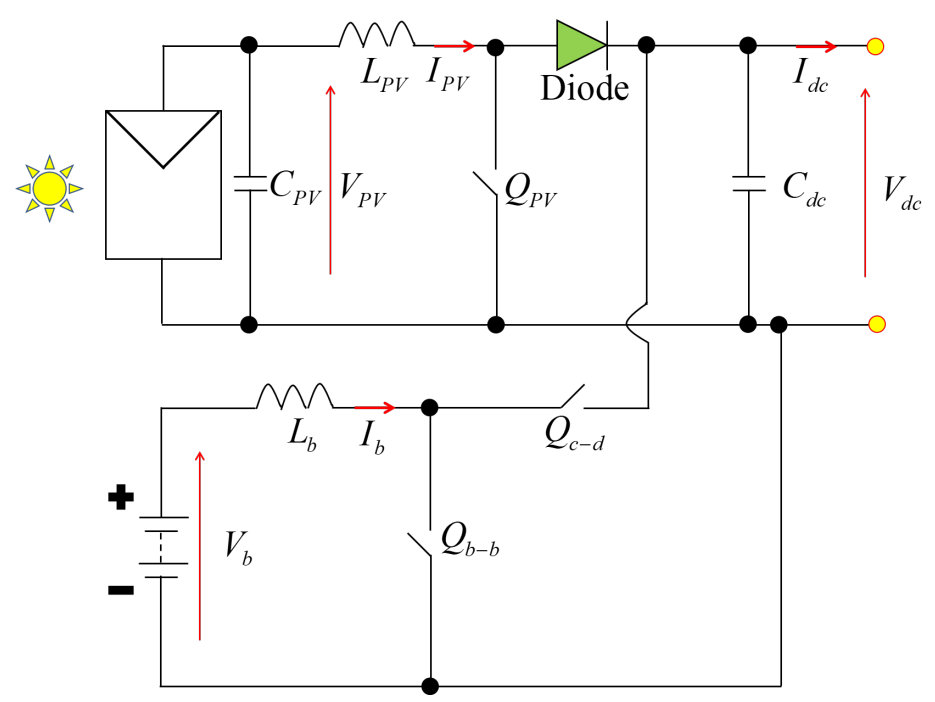

Figure 5. Solar PV with bidirectional buck-boost converter

Denoting the duty cycle of $Q_{b-b}$ and $Q_{c-d}$ as $D_{b}$, one can design the BDC inductor by utilizing (23)-(24) as was done in [Magdi et al., 2017], where the charging current ripple is denoted by $\Delta I_{b}$.

$$
\begin{aligned}
& L_{b}=\frac{D_{b}\left(V_{d c}-V_{b}\right)}{f_{s} \Delta I_{b}} \\
& D_{b}=\frac{V_{b}}{V_{d c}}
\end{aligned}
$$

\subsubsection{Control of battery energy storage system}

The charging and discharging conditions of the battery energy storage system (BESS) are tied to the state of charge (SOC), DC bus voltage, and net power $\left(P_{n e t}\right)$ of the microgrid DERs for the rural standalone system. The $P_{n e t}$ is calculated as (25) [18], where the solar PV power is $P_{P V}$, wind power is $P_{w}$ and the load is $P_{L}$.

$$
P_{\text {net }}=\left(P_{V}+P_{W}\right)-P_{L}
$$

In case there is an excess of power from the sources ( $\left.P_{n e t}>0\right)$, the excess energy is used to charge the batteries. On the other hand, if it is not sufficient to power from the sources $\left(P_{n e t}<0\right)$ the battery energy is discharging as proposed limit of SOC. This proposed battery control scheme is shown by Figure 6. If the battery SOC value is higher than $50 \%$, the BESS discharges and supplies power to the load. The BESS charges when the SOC is less than $100 \%$, while there is excess energy from the two sources. The battery charging and discharging control system utilizes two-loop PI structure, outer loop with $P I_{b 1}$ regulating the BESS voltage, and $P I_{b 2}$ regulating its current. The boost and buckboost converter parameters are found as per Table 2. The capacity of the BESS is $12 \mathrm{~V}, 124$ Ah, which are tabulated in the Appendix's Table 3 [26]. The calculated and tuned con- 
troller parameters of $P I_{b 1}$ and $P I_{b 2}$ are $k_{p b 1}=0.1, k_{i b 1}=1, k_{p b 2}=1$, and $k_{i b 2}=100$ respectively.

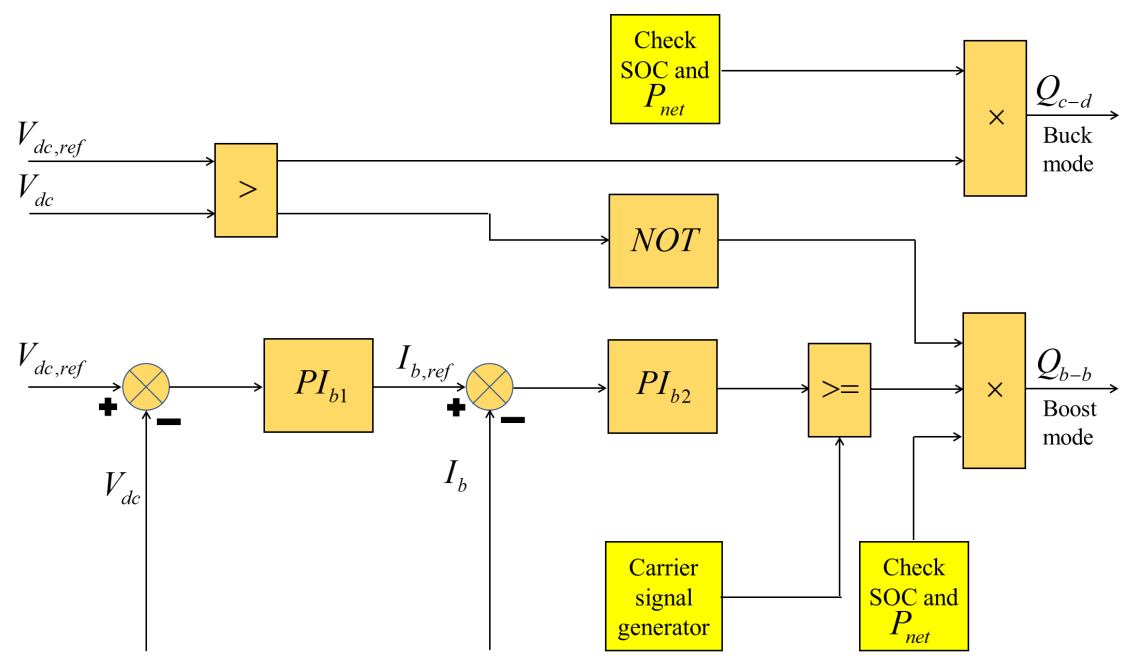

Figure 6. Control of BESS

\subsection{DC bus voltage regulation design for wind generator}

The wind turbine energy conversion system consists of the wind turbine mechanically coupled to the permanent magnet synchronous generator (WT-PMSG). The parameters of PMSG shown in Table 4 [13]. The WT-PMSG is electrically connected to the rectifier, which is further coupled to the DC/DC boost converter. The MPPT is coupled to the rectifier, and tracks the maximum power through rectifier voltage $V_{d}$, and current $I_{d}$ with regards to the wind speeds $V_{w}$ of the WT-PMSG, it then calculates the duty cycle $D_{1}[k]$ as was done by [29], shown in Figure 7. The DC grid voltage is feedback compensated by the PI controller $P I_{w}$ with gains tuned as follows: proportional gain, $k_{w p}=0.00005$ and integral gain, $k_{w i}=25$, which calculates the duty cycle $D_{2}[k]$. Therefore, the control system produces the duty cycle $D_{w}[k]$ by (25) as was done by [12, $30,31]$.

$$
D_{w}[k]=D_{1}[k]-D_{2}[k]
$$

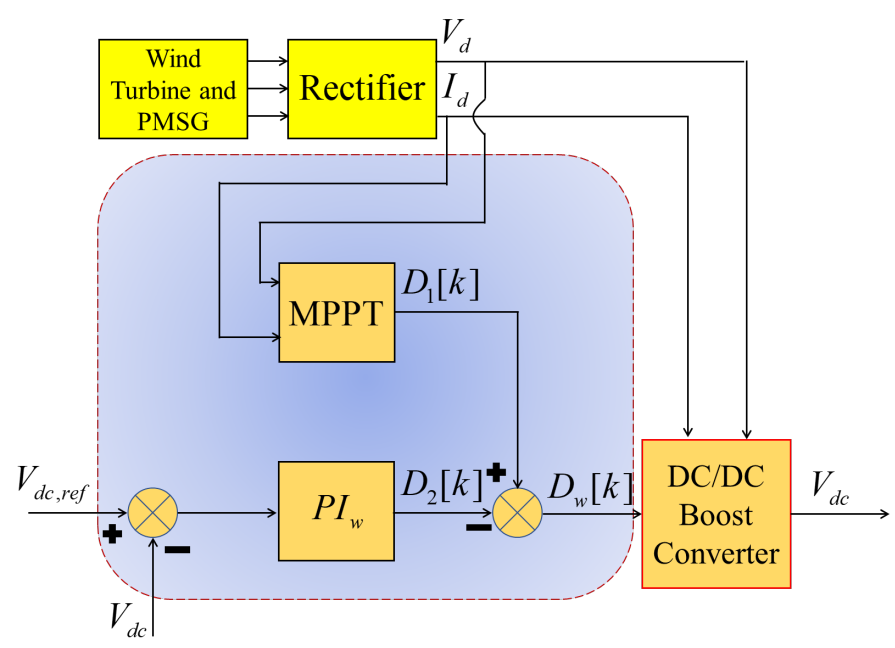


Figure 7. DC voltage regulator of WT-PMSG

\subsection{The hybrid system of solar-wind with battery energy storage system}

The load demand is satisfied by the combination of solar PV, BESS, and WT-PMSG as shown in Figure 8. The WT-PMSG has the input smoothing capacitor $C_{d}$, boost converter inductor $L_{w}$, and its switch $Q_{w}$.

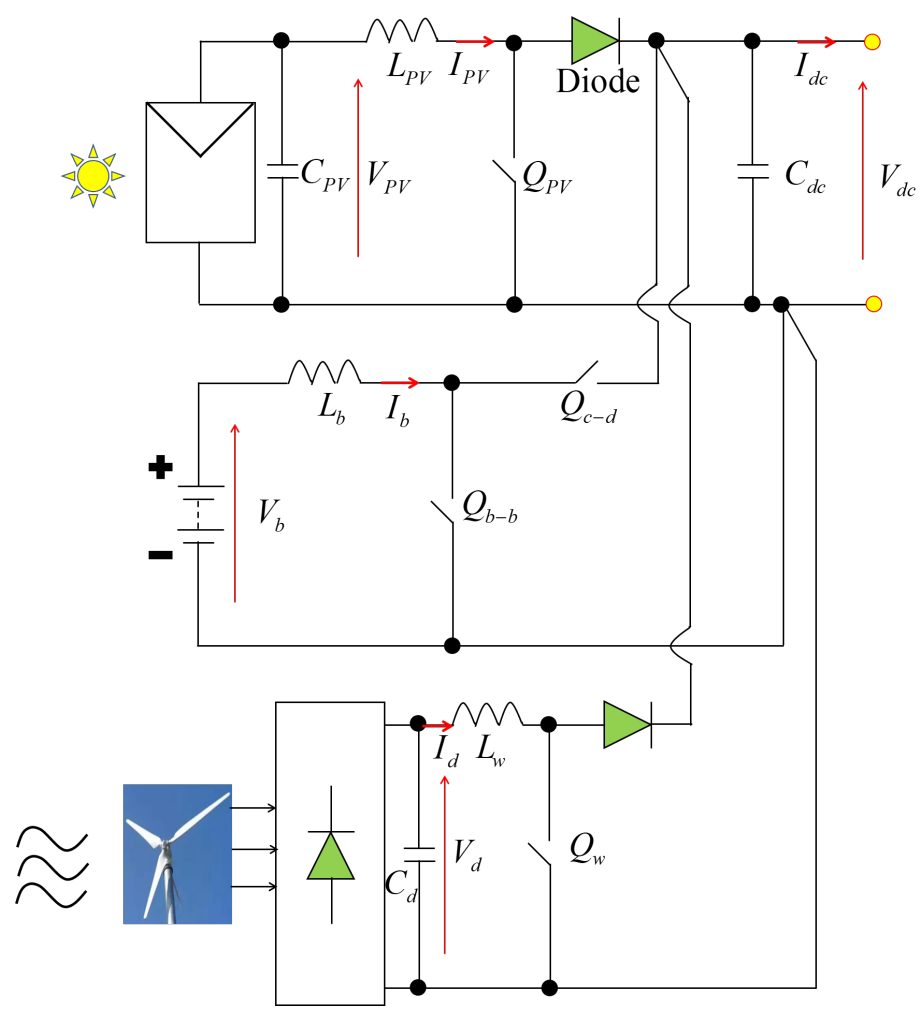

Figure 8. Circuit diagram of microgrid DERs for a rural standalone system

\section{Simulations and Results Discussions}

The circuit diagram of a microgrid DERs for a rural standalone system was built in MATLAB/Simulink software, after design of all system parameters and controller gains. Two case studies were simulated - (1) constant load on the DC grid, and (2) step load changes on the DC grid. Both scenarios considered constant temperature of $30{ }^{\circ} \mathrm{C}$, solar irradiance between $800-1000 \mathrm{~W} / \mathrm{m}^{2}$ as shown in Figure 9. The wind speed was varied accordingly with a mean of $12 \mathrm{~m} / \mathrm{s}$ which translated to angular speed of $150-153 \mathrm{rad} / \mathrm{s}$, as shown in Figure 9.

4.1 Case 1 constant loading of the DC grid

Figure 9 shows that the solar irradiance is $1000 \mathrm{w} / \mathrm{m}^{2}$ from $0-1 \mathrm{~s}$, then it decreases linearly to $2 \mathrm{~s}$. This irradiance is constant till $3.5 \mathrm{~s}$, then it increases linearly to $1000 \mathrm{~W} / \mathrm{m}^{2}$ at $4.5 \mathrm{~s}$. This irradiance is constant until the $6 \mathrm{~s}$ mark. The angular speed is $150 \mathrm{rad} / \mathrm{s}$ from the start till $2 \mathrm{~s}$. The wind speed is increased linearly to $153 \mathrm{rad} / \mathrm{s}$ at the $3 \mathrm{~s}$ time. It stays constant for $1.5 \mathrm{~s}$. Thereafter, it falls linearly to $150 \mathrm{rad} / \mathrm{s}$ at the $6 \mathrm{~s}$ mark. Figure 10 presents the results of the DC grid voltage at the constant loading, where it is observed reference $\left(V_{d c, r e f}=750 \mathrm{~V}\right)$ is tracked by the output voltage $V_{d c}$.

\subsection{Case 2 step load increase of the DC grid}


Figure 11 shows that the load current $I_{d c}$, on the grid starts from 0 at $20 \mathrm{~A}$. It stays the same for one minute. Then it increases step wise to $30 \mathrm{~A}$ and stays the same until 2.5 $\mathrm{s}$. Then it jumps to $40 \mathrm{~A}$ at $2.5 \mathrm{~s}$ until $4.0 \mathrm{~s}$. Thereafter, it jumps to $50 \mathrm{~A}$ at the $4.0 \mathrm{~s}$ mark. It stays this way until the $6.0 \mathrm{~s}$ mark. For all these step load variations, the DC grid voltage followed the reference as shown in Figure 11.

While Figure 12 shows the battery voltage being maintained at $240 \mathrm{~V}$, while the battery current kept on increasing thereby charging the battery, shown by the increment of SOC in the same Figure 12.

Figure 13 shows that the MPPT algorithms (for solar PV and WT-PMSG) could track the maximum power as was desired. Figure 14 shows the solar PV MPPT achieving the MPP for irradiance between $800-1000 \mathrm{~W} / \mathrm{m}^{2}$. While all these happened, the output voltage could track the reference.
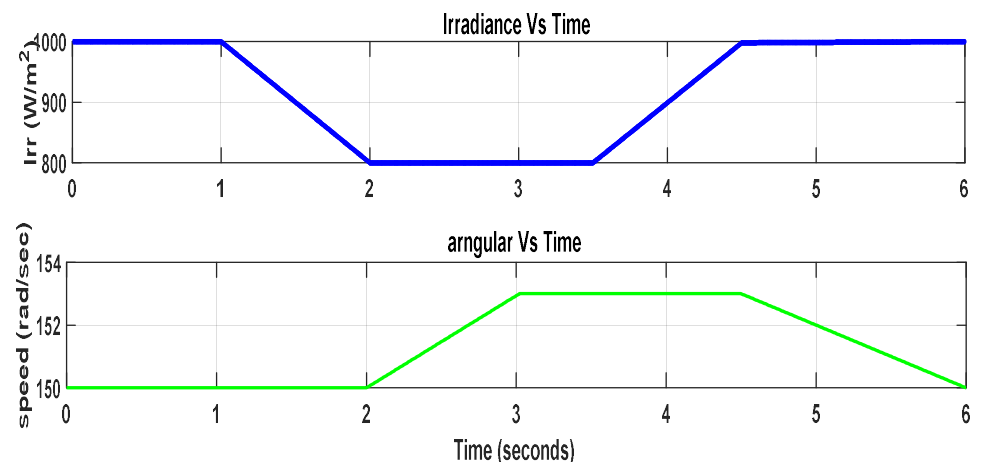

Figure 9. Variations of: solar irradiance Vs time (top curve); and angular speed Vs time (bottom curve)

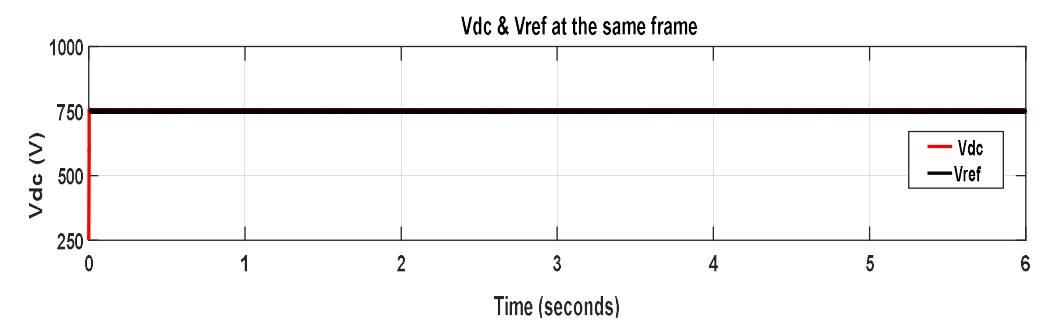

Figure 10. DC grid voltage at constant load
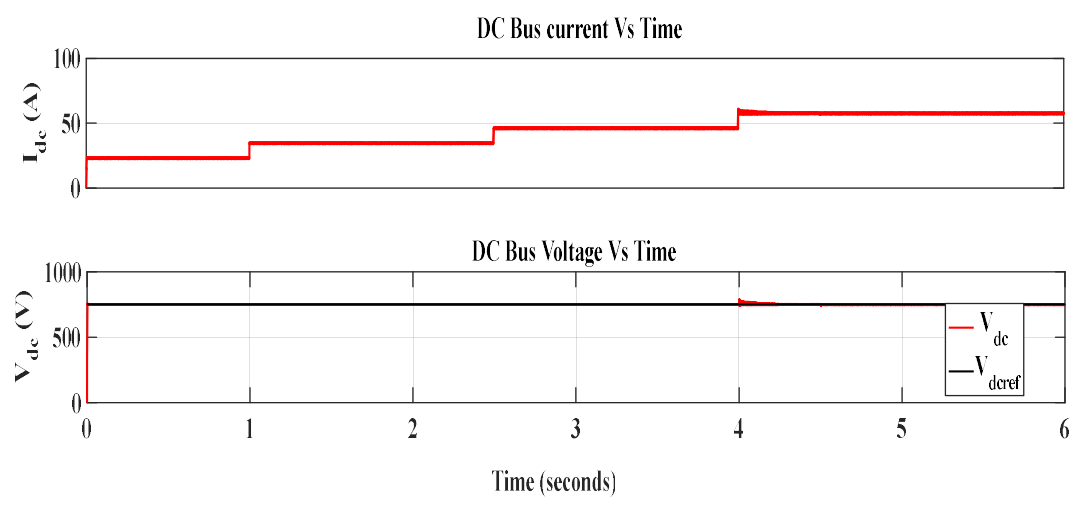

Figure 11. DC bus grid voltage when step load changes 


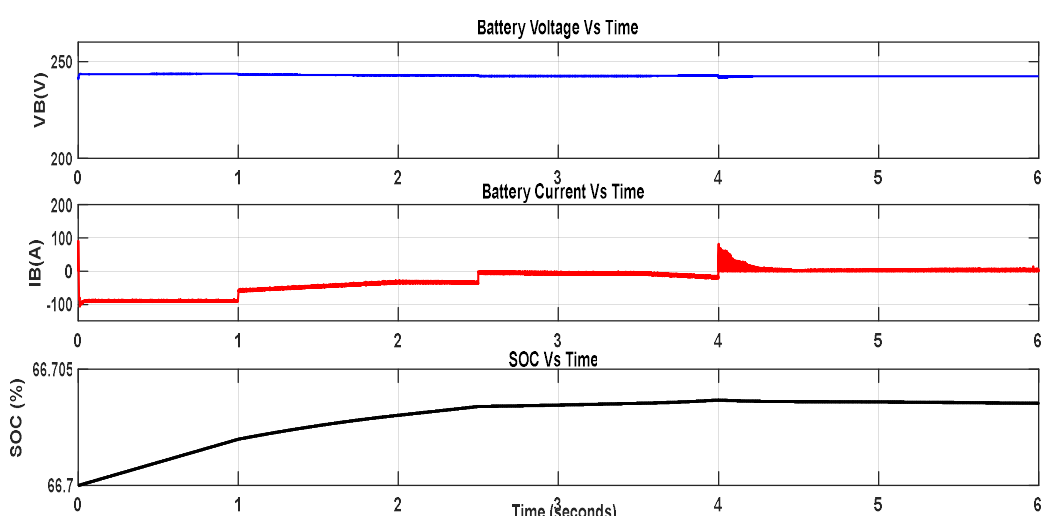

Figure 12. The BESS voltage, current and SOC during the step load change

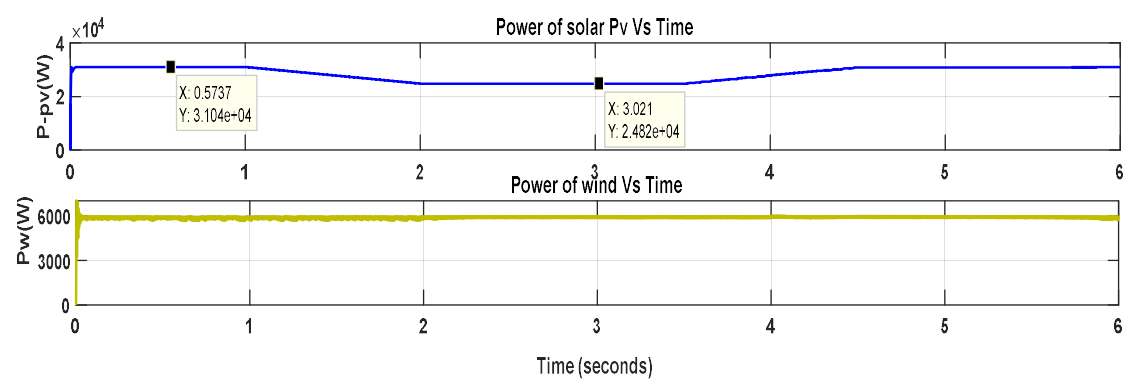

Figure 13. Power from solar PV and WT-PMSG achieved MPP through the MPPT algorithms

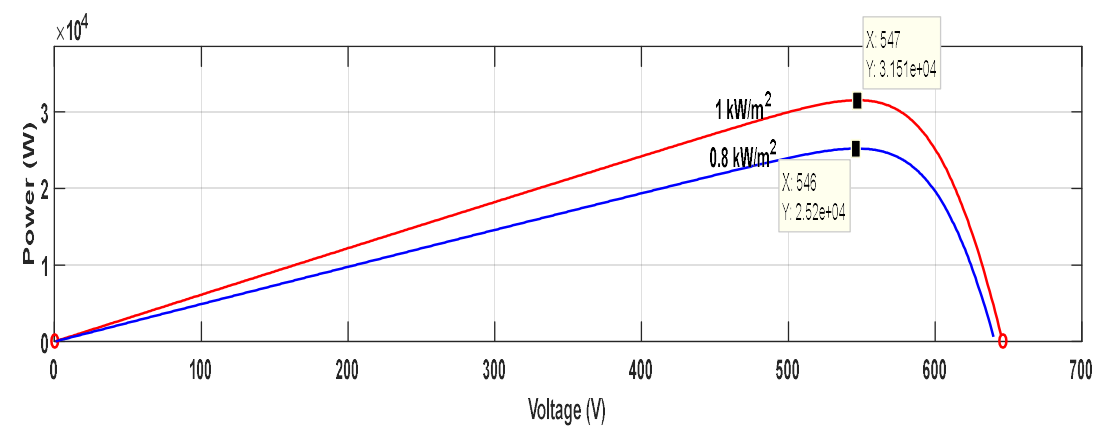

Figure 14. The P-V curve showing MPP at solar irradiance between $800 \mathrm{~W} / \mathrm{m}^{2}$ $1000 \mathrm{~W} / \mathrm{m}^{2}$

\section{Conclusions}


This paper set out to design a DERs standalone microgrid that feeds DC loads. It has discussed the solar PV, BESS, and WT-PMSG and their coupling to the DC grid. The control algorithms used MPPT based PI controllers for maximum power tracking and error compensation. The MPPT employed the P\&O algorithm, while the PI controller gains were tuned by Ziegler-Nichols method. Under the simulations of constant load, varying load, varying irradiance, varying wind speeds, the output voltage of the grid could track the reference fairly well.

This developed prototype could further be tested on a microgrid test bed. However, due to untenable constraints, the simulations alone are presented here. Future work will involve testing the whole DERs microgrid on the test bed and validate its performance. This is a useful research for electrification of islanded areas far from grid connectivity.

Author Contributions: Conceptualization, M.J., and B.M.; methodology, M.J and C.M.; software, M.J.; validation, M.J., B.M., C.M., and A.M.; formal analysis, M.J., and A.M.; writing-original draft preparation, M.J., and A.M.; writing-review and editing, A.M., and C.M.; supervision, C.M. and B.M; project administration, C.M. and M.J. All authors have read and agreed to the published version of the manuscript.

Funding: This research was possible due to financial support of the Royal Society for PhD studentship, Registered Charity No. 207043.

Institutional Review Board Statement: Not applicable.

Informed Consent Statement: Not Applicable.

Data Availability Statement: Data is contained within the article.

Acknowledgments: This research is supported by the Royal Society -DFID in the UK under the Africa Capacity Building Program Initiative. It is implemented by the ACERA consortium: that is the University of Leeds in the UK; CREEC-Makerere University in Uganda; Dar es Salaam Institute of Technology (DIT) in Tanzania and Marien Nguabi University in Congo Brazzaville.

Conflicts of Interest: The authors declare no conflict of interest.

Appendix

Table 1. Solar array sun power SPR-315-WHT-D

\begin{tabular}{lcc}
\hline Parameters & Values & Units \\
\hline Max. power & 315 & $\mathrm{~W}$ \\
Current at MPP & 5.76 & $\mathrm{~A}$ \\
Voltage at MPP & 54.7 & $\mathrm{~V}$ \\
Temperature coefficient of Voc & -0.27269 & $\% /{ }^{\circ} \mathrm{C}$ \\
\%/deg.C) & & \\
Open circuit voltage Voc & 64.6 & $\mathrm{~V}$ \\
Short circuit current Isc & 6.14 & $\mathrm{~A}$ \\
Current/temp. coefficient, Ki & 0.061745 & $\% /{ }^{\circ} \mathrm{C}$ \\
& & \\
\hline
\end{tabular}


Table 2. Parameters of DC/DC converters

\begin{tabular}{lcc}
\hline Parameters & Values & Units \\
\hline Boost Converter for Solar PV & 20 & $\mathrm{mH}$ \\
Inductor $\mathrm{L}_{1}$ & 150 & $\mu \mathrm{F}$ \\
Capacitor $\mathrm{C}_{1}$ & 15 & $\Omega$ \\
Resistive Load $\mathrm{R}_{1}$ & & \\
Boost Converter for wind system & 35 & $\mathrm{mH}$ \\
Inductor $\mathrm{L}_{3}$ & & $\mathrm{mH}$ \\
Back-Boost Converter & 1 & \\
Inductor $\mathrm{L}_{2}$ & & \\
\end{tabular}

Table 3. Lead-acid battery capacity

\begin{tabular}{lcc}
\hline Parameters & Values & Units \\
\hline Nominal Voltage & 240 & $\mathrm{~V}$ \\
Rated Capacity & 248 & $\mathrm{Ah}$ \\
\hline
\end{tabular}

Table 4. Parameter for PMSG

\begin{tabular}{lcc}
\hline Parameters & Values & Units \\
\hline Rated speed & 153 & $\mathrm{rad} / \mathrm{sec}$ \\
Armature resistance, Rs & 0.425 & $\Omega$ \\
Flux & 0.433 & $\mathrm{~Wb}$ \\
Rated current & 12 & $\mathrm{~A}$ \\
Stator inductance Ls & 8.4 & $\mathrm{mH}$ \\
Rated torque & 40 & $\mathrm{Nm}$ \\
Rated power & 6 & $\mathrm{~kW}$ \\
\hline
\end{tabular}

\section{References}

1. Aslam, Z.; Li, H.; Hammerton, J.; Andrews, G.; Ross, A.; Lovett, J.C. Increasing access to electricity: an assessment of the energy and power generation potential from biomass waste residues in Tanzania. Energies 2021, 14, 1793. https://doi.org/10.3390/en14061793.

2. Kinhal, V.; Katti, P.K. Rural electrification through solar and wind hybrid system: a self sustained grid free electric power source. Energy Procedia 2012, 14, 2081-2087. DOI: 10.1016/j.egypro.2011.12.1211.

3. Zhou, W.; Lou, C.; Li, Z.; Lu, L.; Yang, H. Current status of research on optimum sizing of stand-alone hybrid solar-wind power generation systems. Applied Energy, Elsevier 2010, 87, 2, 380-389. DOI: 10.1016/j.apenergy.2009.08.012.

4. Adhikari, S.; Li, F. Coordinated V-f and P-Q control of solar photovoltaic generators with MPPT and battery storage in microgrids. IEEE Transactions on Smart Grid 2014, 5, 3, 1270-1281. DOI: 10.1109/TSG.2014.2301157.

5. Mwinyiwiwa, B.M.M.; Manyahi, M.J.; Gregory, N.; Kyaruzi, A.L. Conceptual synthesis of the multisource renewable energybased micro grid. International Scholarly and Scientific Research \& Innovation 2013, 7, 12, 1687-1692.

6. Tayab, U.B.; Mohd A.R.; Leong, J.H.; Muhammad, K. A review of droop control techniques for microgrid. Renewable and Sustainable Energy Reviews 2017, 76, 717-727, ISSN 1364-0321, DOI: org/10.1016/j.rser.2017.03.028.

7. Mwinyiwiwa, B.M.M. DC bus voltage regulator for renewable energy based micro grid-application. International Scholarly and Scientific Research \& Innovation, 2013, 7, 12, 1629-1633.

8. Maher E.N. Hybrid power systems energy management based on artificial intelligence. PhD Thesis, Manchester Metropolitan University, UK, 2013.

9. Lopes, J.A.P.; Moreira, C.L.; Madureira, A.G. Defining control strategies for micro grids islanded operation. IEEE Transactions on Power Systems 2006, 21, 2, 916-924. DOI: 10.1109/TPWRS.2006.873018. 
10. Madaci, B.; Chenni, R.; Kurt, E.; Hemsas, K. Design and control of a stand-alone hybrid power system. International Journal of Hydrogen Energy 2016, 41, 12485-12496. DOI: 10.1016/j.ijhydene.2016.01.117.

11. Juma, M.; Msigwa. C.; Mwinyiwiwa, B.M.M. Solar PV based on maximum power point tracking embedded voltage regulation for micro-grid application. International Journal of Innovative Research in Advanced Engineering (IJIRAE), 2019a, 6, 6, 552-558.

12. Errami, Y.; Ouassaid, M.; Maaroufia, M. Control of a PMSG based wind energy generation system for power maximization and grid fault conditions. Energy Procedia 2013, 42, 220-229.

13. ELmorshedy, M.F.; Allam, S.M.; Ahmed, I.A.S.; Essam, M.R. Voltage and frequency control of a stand-alone wind-energy conversion system based on PMSG. 2015 4th International Conference on Electric Power and Energy Conversion Systems (EPECS) 2015, DOI: 10.1109/EPECS.2015.7368494.

14. Sahu, S.; Yadav, S.P. Dynamic modelling and control of PMSG based stand-alone wind energy conversion system. Recent Advances on Engineering, Technology and Computational Sciences (RAETCS) 2018, 1-6.

15. Justo, J.J.; Mushi, A.T. Performance analysis of renewable energy resources in rural areas: case study of solar energy. Tanzania Journal of Engineering and Technology 2020, 39, 1, 1-12. DOI: https://doi.org/10.52339/tjet.v39i1.514.

16. Iqbal, M.M.; Islam, K. Design and simulation of a PV system with battery storage using bidirectional DC-DC converter using MATLAB/Simulink. International Journal of Scientific \& Technology Research 2017, 6, 7, 403-410.

17. Haque, M.E.; Muttaqi, K.M.; Negnevitsky, M. Control of a standalone variable speed wind turbine with a permanent magnet synchronous generator. IEEE Power and Energy Society General Meeting-Conversion and Delivery of Electrical Energy in the 21st Century 2008, 1-9. DOI: 10.1109/PES.2008.4596245.

18. Dileep, S.K.; Annapurna, N.V.B. Power quality improvement in standalone battery integrated wind energy system. International Conference on Signal Processing, Communication, Power and Embedded System (SCOPES) 2016, 642-647. DOI: 10.1109/SCOPES.2016.7955519.

19. Mushi, A.; Nagai, S.; Obara, H.; Kawamura, A. Design for nonlinear reference deadbeat control for boost converter. 2017 IEEE International Future Energy Electronics Conference and ECCE Asia (IFEEC 2017 - ECCE Asia), 2017a. DOI: 10.1109/IFEEC.2017.7992118.

20. Mushi, A.; Nagai, S.; Obara, H.; Kawamura, A. Fast and robust nonlinear deadbeat current control for boost converter. IEEJ Journal of Industry Applications, 2017b, 6, 5, 311-319. DOI: https://doi.org/10.1541/ieejjia.6.311.

21. Mushi, A.T. Proposal of Nonlinear Deadbeat Control for Boost Converter and the Experimental Verification. PhD. Thesis, Yokohama National University, Japan, 2017. https://ci.nii.ac.jp/naid/500001044068.

22. Kewat, S.; Singh, B.; Hussain, I. Power management in PV-battery-hydro based standalone microgrid. IET Renewable Power Generation 2018, 12, 391-398.

23. Masenge, I.H.; Mwasilu, F. Modeling and control of solar PV with battery energy storage for rural electrification. Tanzania Journal of Engineering and Technology 2020, 39, 1, 47-58. DOI: https://doi.org/10.52339/tjet.v39i1.518.

24. Mushi, A.; Nozaki, T.; Kawamura, A. Proposal for faster disturbance rejection of boost DC-DC converter based on simplified current minor loop. 2015 IEEE 2nd International Future Energy Electronics Conference (IFEEC) $2015 . \quad \mathrm{DOI}$ 10.1109/IFEEC.2015.7361382.

25. Juma, M.; Msigwa, C.; Mwinyiwiwa, B.M.M. Solar PV based maximum power point tracking embedded DC voltage regulation incorporating battery. London Journal of Engineering Research, London Journals Press 2019b, 19, 5, 31-37.

26. Rajasekaran, R.; Usha Rani, P. Bidirectional DC-DC converter for microgrid in energy management system. International Journal of Electronics 2021, 108, 2, 322-343. DOI:10.1080/00207217.2020.1793418.

27. de Aguiar, C.R.; Fuzato, G.H.F.; Machado, R.Q.; Guerrero, J.M. An adaptive power sharing control for management of DC microgrids powered by fuel cell and storage system. IEEE Transactions on Industrial Electronics 2020, 67, 5, 3726 - 3735. DOI: 10.1109/TIE.2019.2916312.

28. Magdi, S.; Mahmoud, N.M.; Alyazidi, M. I. Adaptive intelligent techniques for microgrid control systems: a survey. International Journal of Electrical Power E Energy Systems 2017, 90, 292-305. https://doi.org/10.1016/j.ijepes.2017.02.008.

29. Muhammad, H.R. Power Electronics Circuit, Devices and Applications. Prentice-Hall, Inc.: London, UK, 1988.

30. Rahimi, M. Modeling, control and stability analysis of grid-connected PMSG based wind turbine assisted with diode rectifier and boost converter. Electrical Power and Energy Systems, Elsevier Ltd 2013, 93, 84-96.

31. Gilbert, M. Renewable and Efficiency Electrical Power Systems. John Wiley \& Sons, Inc.: London, UK, 2004. 